\title{
BIBLIOGRAPHY
}

LAWFORD, J. B. and Collins, E. TREACHER-Sarcoma of the Uveal Tract with notes on 103 cases. Ophthal. Hosp. Reps., Vol. XVIII, p. 104. 1893.

DAvenPoRT, R. C.-A Family of Choroidal Sarcoma. Brit. Ji. Ophthal., Vol. XI, p. 443. 1927.

Pfingst, A. O.-Melano-sarcoma of the Choroid occuring in Brothers. Arch. Ophthal., Vol. L, p. 431. 1921.

Lawrence, W.-Melanosis of the eye. London Med. Gaz., Vol. XXXVI, p. 961. 1845.

HULRE, J. W. - Case of Sarcoma of Choroid associated with pigment spots on lids and sclera. Ophthal. Hosp. Reps., iii. 1860.

MARTIN, C.-Case reported. Virchow's Arch., Vol. CXXXVIII, p. 111.

JULER, F.-A case of unilateral melanosis oculi with development of a sarcoma. Trans. Ophthal. Soc. U.K., Vol. 56, p. 121. 1936.

DoherTy, W. B.-Melanosis Oculi. Amer. Jl. Ophthal., Vol. X. 1927.

Conts, G.-Report on collected cases of nævi of the iris. Trans. Ophthal. Soc. U.K., Vol. XXXIII, p. 165.

HirschBerg, J.-Report on cases of nævi of the iris. Jl. Amer. Med. Assoc., Vol. XLV, p. 1617.1905.

Collins, E. Treacher-Discussion on the Melanomata. Trans. Ophthal. Soc. U.K., Vol. XLVI, p. 74. 1926.

MoORE, R. Foster-Discussion on the Melanomata. Trans. Ophthal. Soc. U.K., Vol. XLVI, p. 74.1926.

Scheerer, R.-Melanosis Choroidex. Ergebn.d. allg. Path. v. Path.-Anat. Vol. XXI, p. 91.1928.

SCHAPPERT-KIMMYSER, J.-Die frequenz sogenannten uveal melanosis Augen mit und ohne Sarkom. Arch.f. Augenheilk., Vol. XLVI, p. 100. 1929.

WAGENER, H. P. and WELLBROCK, W. L.-Melanoma becoming malignant. Arch. of Ophthal.. Vol. IV, p. 509.1930.

EwING-Text-book of Neoplastic Diseases.

Parsons, J. H.-Pathology of the Eye, ii, p. 498.1905.

Verhoeff, F.-Trans. Sect. Ophthal. Amer. Med. Assoc., p. 159. 1934.

NiTSCH, M.-An inquiry into the causal relationship between trauma and choroidal sarcoma. Zeitschr. f Augenheilk., Vol. LVII, p. 225.1925.

Coleman, W. F.-Case Report. Ophthal. Rec., Vol. IX, p. 611. 1901.

KIPP, C. J.-Case Report. Ophthal. Rec., Vol. XIV, p. 271. 1905.

ChANCE, B.-Case Report. Amer. Jl. Ophthal., Vol. XVII, p. 48. 1934.

Holloway, T. B.-Case Report. Amer. Jl. Ophthal., Vol. XV, p. 961. 1932.

STEIREN, M. D.-Sarcoma of the Uveal Tract following Trauma. Trans. Sect. Ophthal. Amer. Med. Assoc., p. 149. 1934.

LANÉ, A. L. - Discussion on trauma and choroidal sarcoma. Trans. Sect. Ophthal. Amer. Med. Assoc., p. 159.1934.

NeAme, $H$. and WAJID ALI KHAN-Glaucoma secondary to choroidal sarcoma: treatment of blind glaucomatous eyes. Brit. Jl. Ophthal., Vol. IX, p. 618. 1925.

Parsons, J. H.-Pathology of the Eye, ii, p. 524. 1905.

EWETzKY-Cercle Ophthal. de Moscow. 1897.

LEBER and KRAHNSTOVER-Arch.f. Ophthal., Vol. XLV, p. 1898.

NETTLESHIP, E.- Sarcoma of the choroid in an eye affected with gross choroiditis of an earlier date. Trans. Ophthal. Soc. U.K., Vol. XXIV, p. 93. 1903-4.

Glover, L. P.-Melanotic Sarcoma arising from area of choroido-retinitis Amer. Jl. Ophthal., Vol. XVI, p. 337. 1933.

\section{VISUAL ACUITY}

This was noted in 192 of the total number of cases recorded, and in 71 cases $I$ have been unable to ascertain the vision.

It will be seen from the table of visual acuity that the majority of patients (74, or 38.5 per cent.), present themselves for examination with sight reduced to no perception of light, while 24 , or 
12.4 per cent., come under observation with useful vision, $6 / 18$ or better, 5 of these having $6 / 9$ and 5 having $6 / 6$.

\begin{tabular}{ccccc} 
Vision & & $\ldots$ & \multicolumn{2}{c}{ No. of Cases. } \\
$6 / 6$ & $\ldots$ & $\ldots$ & $\ldots$ & 5 \\
$6 / 9$ & $\ldots$ & $\ldots$ & $\ldots$ & 5 \\
$6 / 12$ & $\ldots$ & $\ldots$ & $\ldots$ & 1 \\
$6 / 18$ & $\ldots$ & $\ldots$ & $\ldots$ & 13 \\
$6 / 24$ & $\ldots$ & $\ldots$ & $\ldots$ & 5 \\
$6 / 36$ & $\ldots$ & $\ldots$ & $\ldots$ & 5 \\
$6 / 60$ & $\ldots$ & $\ldots$ & $\ldots$ & 18 \\
Counts fingers & $\ldots$ & 20 \\
Hand movements & $\ldots$ & 22 \\
Perception of light & $\ldots$ & 24 \\
No perception of light & 74 \\
\multicolumn{4}{c}{ Total } & \multicolumn{3}{c}{192} \\
\end{tabular}

The symptoms and signs of an intra-ocular sarcoma differ'so markedly during the course of the disease that four stages are commonly distinguished and there appears to be no valid reason for departing from this well known division.

\section{First Stage.}

This may be called the quiescent period. If the subject is seen in this stage the complaint is generally one of visual disturbance of some kind or other.

The usual one is of a defect or blur in the visual field corresponding to the site of the tumour or detachment-but loss of central vision may be the symptom complained of in those cases of growth situated at or near the macula. Externally the globe appears normal and on ophthalmoscopic examination a detachment of varying size will be noticed.

Later in this stage the detachment may become much more extensive and the visual acuity very much affected, although externally the eye still shows no pathological signs.

\section{Second Stage.}

Many patients present thémselves for examination for the first time when the growth has proceeded to the glaucomatous period of its course; diagnosis is now much more difficult. The usual complaint is one of defective vision for some time, gradually getting worse, with pain in the globe and surrounding tissues.

Externally the eye presents the signs of inflammatory glaucoma, marked ciliary injection and corneal oedema, and a definite rise in intra-ocular tension is present. 
Dilatation of the anterior ciliary vessels overlying the growth may be observed, and 'when present is an important diagnostic sign.

Dilatation of the vessels in the iris, in a quadrant corresponding to the site of the choroidal tumour is occasionally observed, and it is stated that corneal anaesthesia in thel same quadrant may be noted, due to pressure on the nerves as they pass through the choroid.

This anaesthesia is, I think, an unreliáble sign, since oedema of the cornea by itself can cause a diminution in the corneal sensibility.

If the cornea and intra-ocular media are sufficiently clear to allow an ophthalmoscopic examination, the retina will now be observed to be detached over a wide area, a secondary detachment due to irritative exudation from the choroidal vessels being present as well as the detachment due to the growth itself.

\section{THIRD Stage.}

In this stage the neoplasm has perforated the globe, pain is lessened due to the lowering of the intra-ocular tension.

The clinical picture depends on whether this perforation has occurred anteriorly or posteriorly.

-If the former be the case, a large mass will be seen growing from the front part of the globe; if the latter, little may be seen at first, but later progressive proptosis occurs, which may be occasionally masked by the globe shrinking into the condition of phthisis bulbi.

During this stage the growth, freed from the confines of the sclera, rapidly increases in size : haemorrhages are common and the disease enters upon its final stage.

\section{Fourth Stage.}

This is the period of generalised metastases.

The tumour cells are carried, probably by an embolic process, to remote organs, most frequently the liver, and the patient dies usually from cachexia or metastatic cerebral complications.

For a sarcoma of the uveal tract to proceed through the four stages described may take a very considerable time, and these stages in periods of time may vary enormously from case to case.

The first and second stages may last for years, or the glaucomatous stage may rapidly replace the quiescent period, the size of the growth within the eye apparently having little relationship to the increase in intra-ocular pressure, very small growths sometimes causing this phenomenon.

Stage four, that of general metastases may occur very early without the intervention of ocular perforation in stage three. 
The third stage is not commonly seen now, but if ocular perforation has occurred the disease usually rapidly progresses towards its invariably fatal termination.

Sarcoma of the ciliary body progresses throughout the same four stages as are observed in the case of choroidal sarcoma, the growth being fundamentally of the same nature and giving rise to similar symptoms.

If the growth is confined to the ciliary body, the retina is not usually detached, as its attachment is firm in this position; retinal detachment occurs, however, directly the choroid is involved by local spread of the growth.

The sarcoma sometimes grows forward into the angle of the anterior chamber, causing marked symptoms and signs due to interference with the ciliary muscle and position of the lens. Sarcoma of the iris may give rise to no subjective symptoms at all, the neoplasm only being discovered on routine examination.

In other cases the patients generally seek advice, stating that they have a small brown or blackish spot on the coloured part of their eye which they think may possibly have increased in size recently ; they may state that the spot had been present for as long as they could remember, or that they had been born with it.

An unusual symptom is that of recurrent haemorrhages (from the neoplasm) into the anterior chamber of the eye. Such a case is described in the appendix to this paper.

The neoplasm may grow over the pupillary margin of the iris and so interfere with the vision.

If the tumour increases markedly in size, the intra-ocular tension will rise, still further interfering with the visual acuity; the neoplasm may then be seen as a large brown or blackish mass, rarely unpigmented, growing into the angle of the anterior chamber.

The neoplasm occasionally perforates the globe; if this be the case a fungating mass will be noticed, at or near, the limbus, the perforation usually occurring via the perforating ciliary vessels.

\section{DIAGNOSIS}

The ability to make a correct and rapid diagnosis in the case of a malignant neoplasm is the essence of good treatment, the quicker the diagnosis, the better chance the patient has for a so-called "cure."

In many positions in the body the diagnosis of a neoplasm may be somewhat uncertain, but no great harm will accrue if the suspicious growth or area in which the suspected growth is situated be removed, the part still being able to function normally 
or nearly so, it mattering little from the patient's point of view whether the diagnosis is correct or not.

There are, however, certain positions within the body in which a growth may be situated or suspected, which after removal, leave the surgical legacy of dysfunction and it is a tragedy if the part or tissue has been removed unnecessarily.

To remove an eye, although it be blind, leaves the individual concerned at a considerable cosmetic disadvantage, but it is sound treatment to do so in every case unless it is certain that the eye does not contain a malignant growth:

Sometimes the vision of the affected eye is useful or even normal and the patient young and most unwilling to sacrifice the eye, but the malignancy of the neoplasm makes action imperative.

In the majority of cases of intra-ocular neoplasm the diagnosis presents no special difficulties, but in doubtful cases it may be most confusing, and every aid to arriving at a correct diagnosis should be employed.

Clinical History.-When confronted with a suspicious intraocular mass, a careful history of the case should be taken, as it may give the clue to the diagnosis, or at least not infrequently lend a valuable aid to this end. So often the disease is seen on the first occasion when the globe is in a condition of secondary glaucoma, with the cornea oedematous and the ocular media so hazy as to make an ophthalmoscopic examination impossible.

In these cases, acute primary glaucoma, haemorrhagic glaucoma (due to occlusion of the central retinal vein) and glaucoma secondary to intra-ocular neoplasm constitute the differential diagnosis.

In primary glaucoma it is not unusual after careful questioning to find that there have been attacks of interference in vision, alternating with remissions, in which the visual acuity has been normal or nearly so. The fellow eye may also have been affected.

In haemorrhagic glaucoma the vision has suddenly become bad, with perhaps some subsequent improvement, then the onset of pain and glaucoma.

In the case of intra-ocular neoplasm with increased intra-ocular tension, it is more usual than not to find the vision has been bad for some time with a gradual increase in the failure, remissions being uncommon.

The onset of symptoms may, with other factors, help one to arrive at a correct diagnosis; the statement from a patient of sudden loss of vision in some part of the visual field, subsequent, perhaps, to slight trauma and in a myopic eye, is more in favour of an idiopathic detachment than one due to growth. But Lister quotes " a sudden onset may only mean a belated discovery of a more or less long standing visual loss," and this point must be 
borne in mind if any weight is to be placed on the patient's word as an aid to diagnosis.

In the present series of cases under investigation, the average duration of symptoms prior to seeking advice was as long as nineteen months. This average, however, includes those cases in which the eye containing the neoplasm had previously been the seat of inflammatory or itraumatic conditions.

A short history is generally found in cases suffering from a simple detachment, but it must be remembered that patients with sarcoma of the choroid are generally elderly or past middle age, and have reached that state of life in which failure of sight is looked upon, especially in the hospital type of patient, as not an uncommon occurrence, this factor alone causing delay in seeking advice-a very different state of affairs to a similar happening in most younger patients.

\section{Clinical signs.}

Retinal Detachment.-This may be symptomatic or idiopathic, the former being produced by some known pathological process, the cause for the latter being uncertain.

The detachment caused by a sarcoma of the choroid is for the most part, a solid elevation of the retina pushed up by the growth itself, but in many cases there is a secondary detachment of the retina in some other part of the fundus, which simulates very closely, and is sometimes identical with, an idiopathic detachment, confusing the diagnosis.

The following points help to distinguish a detachment due to growth from the idiopathic variety.

The detachment in growth usually rises very abruptly from the surrounding fundus, is more solid in appearance and may present a yellowish brown colour.

Pigment disturbance in the detached portion is occasionally seen in idiopathic detachment, but when present is more likely to be seen in the case of a detachment due to growth. In most cases the general colour of a detachment caused by growth is darker than the rest of the fundus, while in an idiopathic detachment the detached portion is lighter in colour than the rest of the fundus.

New vessels are sometimes seen on the summit of a detachment due to growth. This is probably a late occurrence, and when present one is almost certainly dealing with a neoplasm.

The detached retina in idiopathic cases is thrown into folds that move when the eyes alter their positions, this does not occur in the detached retina overlying a neoplasm, and seldom occurs to any great extent in the folds of the detachment secondary to the neoplasm, as the inter-retinal fluid in these cases has a higher albuminoid content and is more "solid" than the inter-retinal fluid in idiopathic detachment. 
The diagnostic value of a retinal aperture is said to be of great importance, and is said never to occur in cases of neoplasm.

Lister stated in 1924 that the presence of a hole excluded the presence of a growth, and that he had not seen or read of 1 patient in whom they existed together.

I have personally never observed a case of sarcoma of the choroid in which a tear or hole in the retina has been found, and there is no note of such occurring in any of the cases studied.

Senile macular exudative retinitis.-A solid detachment of the retina which may simulate very closely a choroidal neoplasm is that caused by senile macular exudative retinitis, and there are cases on record of such eyes being removed for new growth. Such is a case reported by Carl Behr in 1929.

The condition is seen in elderly patients, the average age of seventeen cases reported by Davenport being seventy-five years of age, three only of the seventeen being under seventy.

The condition is almost invariably bilateral in the neighbourhood of the macula, one eye being affected more than the other; this bilateral occurrence is a valuable diagnostic point.

The mass is whitish yellow in colour, but may show some brownish pigment near the centre, with new vessel formation.-

Not infrequently exudate surrounds the mass, similar in appearance to a retinitis circinata, another diagnostic point of importance.

Retinal haemorrhages are invariably present and there is sometimes a tongue of exudate running temporally from the mass.

The condition is probably a chronic degenerative process due to arteriosclerosis of the choroidal vessels.

Hydatid cyst. - This is another possible pitfall in diagnosis. The condition is, however, extremely rare in this country, although much more common abroad, many cases having been reported.

The diagnosis is not difficult unless the ocular media are hazy, when the condition may be puzzling. Skin tests should be employed if there is a suspicion of this condițion being present.

Melanoma of the choroid.-This is a benign and probably congenital aggregation of pigment in the choroid, slate grey in colour, situated near the disc, with elevation rarely sufficient to be measured clinically.

The outline of the patch is distinct and there is no disturbance of the retinal pigment, and there is seldom any difficulty with regard to diagnosis.

One would expect a blurring of the edge of the patch and a disturbance of the retinal pigment epithelium overlying the patch to be early signs of malignancy. This has not been observed clinically, although cases are recorded of benign melanoma of the choroid becoming malignant. Wagener and Wellbrock in 1930 
reported such a case, and a doubtful case is reported from the present series in the appendix to this paper.

Detachment of the choroid.-A serous detachment of the choroid occurs not infrequently after intra-ocular operations upon the globe, especially in the case of trephining for glaucoma, and less frequently after cataract extraction.

It is, however, exceptional to see this condition in globes that have not been subjected to previous operative procedure or perforating injury.

The detached choroid appears as a dark prominence projecting into the vitreous chamber and the overlying retina is not thrown into folds.

The diagnosis is generally easy, especially if the condition occurs a short period after an operation or injury.

Cases are on record, however, of eyes presenting the appearances and clinical history of a tumour of the choroid, which, on enucleation, proved to be, in the case reported by Würdemann and Verhoeff, a spontaneous separation of the choroid and in the case recorded by Grigler, a massive annular sub-choroidal haemorrhage.

Other conditions which occasionally cause confusion are localised inflammatory exudates, retinal cysts and, rarely, choroidal or retinal tuberculosis or syphilis, and secondary carcinoma and sarcoma.

Intra-ocular tension is a valuable aid to diagnosis-it being, in idiopathic detachment, normal or subnormal, but a detachment in a glaucomatous eye is much more in favour of intra-ocular neoplasm.

Some observations on intra-ocular tension in sarcoma of the uveal tract will be found at the end of this section.

The diagnosis of iris tumours.-This is, in the majority of cases, extremely difficult and from the diagnostic point of view they can be divided into pigmented and non-pigmented masses, situated in, or upon the iris.

Pigmented.-The most important of these are iris melanomata and sarcomata. At the first examination and in the early stages; it is impossible in many cases to distinguish between the two, unless the mass is removed by an iridectomy and examined with the microscope.

Only by regular observation and careful notes on the size of the tumour, together with the patient's own story, can one ascertain whether a process of growth is proceeding or not.

Characteristically the innocent melanomata only reach a certain size and remain so. They do not as a rule project much above the plane of the iris, but if the mass starts to increase and grow into the angle of the anterior chamber, the diagnosis of sarcoma must be made. 
If the motility of the iris is disturbed and the pupil margin irregular, the case is very suspicious of malignancy.

The position of the tumour on the iris is of some importance in diagnosis, the commonest place for iris sarcomata being in the lower quadrants.

In all suspicious cases the pupil should be fully dilated with a mydriatic, mydricaine is useful here, and the fundus examined as far forwards as possible, since the ciliary body is sometimes involved by growth with little evidence of malignancy on the iris.

The vascularity of melanotic sarcoma of the iris is variable, but is very marked in some cases, and if this be so, the diagnosis is more likely to be sarcoma than melanoma, vascularisation being very uncommon in the innocent tumour.

Non-Pigmented.-These tumours include non-pigmented sarcoma, gumma, solitary tubercule, granulation tissue round a foreign body and iris cysts.

Leuco-sarcomata of the iris are very rare, according to DukeElder and Stallard in 1930; only twenty-six cases are recorded in the literature. The general position of the growth on the iris is the same as the pigmented variety, nineteen of the twenty-six cases reported being situated in the lower half of the iris.

Gummata of the iris are rare and generally situated at the ciliary or pupillary margins of the iris, never in other positions, according to Fuchs.

These gummata are seldom vascularised to any great extent, iritis is not uncommon, and the blood Wassermann is generally positive.

Tuberculous tumours are also rare and are often surrounded by small satellite nodules of the same character. They are normally observed in children or young adults, and accompanying iritis is common.

The mass of granulation tissue surrounding a foreign body is usually heavily vascularised and reddish in appearance.

The clinical history is somatimes helpful in these cases, but may be quite negative. Evidence of perforation of the globe should be looked for, and an X-ray may reveal the presence of an opaque foreign body embedded in the iris stroma.

A cyst of the iris is an extremely uncommon condition, and may develop after a penetrating injury of the globe, or may be congenital in origin. These cysts are situated within the iris stroma, and appear as greyish transluscent tumours containing a thin serous fluid.

Expanded iris tissue may be seen on the anterior wall of the cyst. Some congenital cysts appear more solid and are filled with a thick pultaceous material-these are the so-called " pearl " cysts. 
Special Aids to Diagnosis.

1. Transillumination.

2. Corneal microscope and slit-lamp.

3. Binocular ophthalmoscope.

4. Diagnostic scleral puncture.

5. Exploring needle.

6. Scleral flap dissection.

7. Rhysical and biochemical examination

Transillumination.-This is a most valuable aid to diagnosis, and should invariably be employed in cases of retinal detachment and painful glaucomatous eyes.

The value of transillumination depends upon the fact that light is transmitted through detached retina. If there is an opaque structure beneath the retina this is, revealed as a shadow.

Transillumination can be used almost equally well when the lens is opaque, rendering ophthalmoscopic examination impossible, and the presence of a vitreous haemorrhage, unless it be very large, does not interfere to any great extent with the method.

It is a good plan to transilluminate the sound eye before examining the affected one. In some cases the ciliary region is more opaque than usual, casting a well marked shadow, and it is necessary to take into consideration the effects of varying pigmentation.

There are two main methods of transillumination, the transconjunctival and the trans-scleral. The former is the one most commonly employed.

Transconjunctival transillumination.-There are various instruments provided and most are quite satisfactory. The important points to bear in mind are that the light shall be of the required intensity, and that the whole of the instrument, apart from the actual point in contact with the conjunctiva, is opaque to light, thereby reducing the scattering of the light rays to a minimum.

It is also important to make sure that the light point of the instrument is behind the ciliary body region, as this normally throws a shadow.

With the lamp in position the normal red reflex can be examined with the naked eye. If the light point lies over an opaque structure the transmission of light is interfered with, and the normal red reflex is replaced by a shadow.

Trans-scleral transillumination.-Post equatorial sarcomata are not readily demonstrated by the ordinary transconjunctival method, and in those cases of tumour situated close to the macula or disc trans-scleral transillumination must be employed, the transconjunctival method being unapplicable.

The type of instrument used for this trans-scleral procedure consists of a metal tube shaped to approximate the contour of the 
globe. Near the end of the tube, on the concave surface, is situated a simall aperture through which the light is emitted.

The conjunctiva and Tenon's capsule are incised and the lamp carefully passed into the incision and backwards.

The possibility of injury to a vortex vein and to a posterior ciliary vessel or nerve does certainly exist in this method, but the risk is small and justified by the gravity of the case under investigation.

The fundus is examined in the same way as in the transconjunctival method of transilluminating.

If a shadow is seen on transitluminating an eye it may be due either to a growth, haemorrhage or exudate. An example of the last possibility is described by Shoemaker and De Long.

The patient was a man aged seventy-three, who showed a large detachment of the retina without any movement of the detachment on altering the position of the eye.

Transillumination gave an extensive shadow and the diagnosis of sarcoma was made. The eye was enucleated, but on microscopic examination a serous exudate was discovered lying between the choroid and retina, with no evidence of a neoplasm.

It has been stated that unpigmented sarcomata occasionally cast little or no shadow on transillumination, but I think that this statement is erroneous; any opaque mass obviously must interfere to some extent with the transmission of light rays, but the degree of pigmentation may alter the density and extent of the shadow.

Corneal microscope and slit-lamp.-This is of use in examining the anterior chamber for the presence of pigmented cells which are sometimes seen in cases of malignant intra-ocular growth, without any evidence of intra-ocular inflammation being present.

It is also of great importance in cases of growths situated upon the iris, the malignant extension from the original area of growth being well shown, and alterations noted on subsequent examinations if the diagnosis be doubtful.

In anterior detachments of the retina, with a clear lens the surface details of the detachment can be seen with the slit-lamp, pigmentary disturbance, new vessel formation and haemorrhages being well revealed.

Pigmented cells may also occasionally be observed in the vitreous, this adding weight to the diagnosis of malignancy in suspicious cases.

Binocular ophthalmoscope.-This instrument is useful in examining detachments situated at the posterior pole of the eye, the stereoscopic vision so obtained showing up details of the detachment in a most striking manner, and revealing the transparency of the retina in idiopathic detachment in marked contrast to that observed in detachment due to a growth beneath it.

The use of " red free" light may reveal very early new vessel 
formation and minute haemorrhages on the detached retina, which may escape notice using " white" light for the examination.

Diagnostic scleral puncture.-This is performed with a small hypodermic syringe armed with a very sharp needle, with not too fine a bore.

A small flap of conjunctiva is first reflected over the site of the retinal detachment and the needle inserted through the sclera, inter-retinal fluid being removed if possible.

On removing the needle, the track in the sclera is immediately sealed with either the cautery, diathermy electrode or pure carbolic acid, the conjunctival flap then being sutured back into position.

At this stage it is useful to examine the fundus and see whether there is any diminution in the volume of the detachment. If fluid has been removed a thin film is immediately made on a slide and after drying examined with the microscope, malignant cells, if present, being readily recognised. This procedure is considered unjustified and dangerous by many authorities.

Zentmayer reports the case of a young man, upon whom he employed this diagnostic puncture. Malignant cells were discovered in the fluid removed, the eye was enucleated and was found to contain a malignant melanoma.

Recurrence of the growth appeared in the orbital tissues soon after enucleation, and this he ascribed to cells having been liberated by the scleral puncture.

I myself think the procedure is rarely justified unless all other methods of arriving at a diagnosis have failed, and still suspicion remains as to the nature of the detachment.

A negative finding on microscopic examination is of little help, but if malignant cells are present in the withdrawn fluid, enucleation should be carried out immediately, and it is important for the surgeon to obtain permission to do this if necessary before employing scleral puncture.

If the puncture is carried out as explained, there is little chance of cells growing along the track of the needle and involving the conjunctiva.

Exploring needle.-This was first described and used by Silcock in 1900. The needle is passed through the sclera in the quadrant opposite the detachment and observed with the ophthalmoscope.

The retina is pierced, care being taken not to puncture a retinal vessel, or the escaping blood will obscure the examination. If the detachment is solid, a sense of resistance will be felt and blood may escape from the puncture in the retina.

Neither of the cases recorded by Silcock happened to be a growth, and this he judged by the fact that no blood escaped from the retinal puncture. 
Two cases described by Ballantyne in 1922, however, were neoplasms, and in each case he was conscious of a resistance and blood oozed from the retinal puncture.

Scleral flap. - A triangular scleral flap may be dissected over the detachment and very carefully raised so as not to disturb the growth beneath it, if such exists.

There are few, if any, cases in which a diagnosis cannot be made without this procedure, which is, I think, highly dangerous and unjustified on account of the risk of local malignant spread.

Physical and biochemical examination.-A routine physical examination of the patient should invariably be carried out, especial attention being noted of the liver, this being an extremely common situation for metastases in this particular neoplastic disease.

If this organ be enlarged, and the Thormahlen test for melanogen in the urine positive, there is no advantage in removing the primary neoplasm in the eye, all such patients succumbing to the disease in the space of a few months.

The urine of many patients in the present series was examined on many occasions, melanogen being found in three cases only. These three patients had grossly enlarged livers and very soon dièd.

It appears from these investigations, and the general view is held, that melanogen is not present in the urine in amounts sufficient to be demonstrable by the chemical tests at present known, unless the liver be enlarged with metastatic deposits of growth.

In this paper no experimental work has been undertaken on the subject of melanogen in the blood or serum of cases with intraocular neoplasm, but on careful inquiry in the proper quarters it appears that no such test is at present known.

\section{BIBLIOGRAPHY}

LISTER, SIR W.-Brit. Jl. of Ophthal., Vol. VIII. 1924.

DAVENPORT, R. C.-Senile Macular Exudative Retinitis. Trans. Ophthal. Soc. U.K., Vol. XLVI, p. 137. 1926.

BEHR, C.-Zeitschr.f. Augenheilk.

WAGENER, H. P. and WELLBROCK, W. L.-Arch. of Ophthal., Vol. IV, p. 509. 1930.

WÜRDEMANN, H. V. and VERHEOFF, F. A.-Spontaneous separation of the choroid simulating choroidal sarcoma.-Amer. Jl. Ophthal., Vol. X, p. 479. 1927.

CRIGLER, L. W.-Sub-choroidal hæmorrhage diagnosed as sarcoma of the choroid. Arch. of Ophthal., Vol. VIII, p. 690.1932.

Morax, V.-Cancer de l'appariel visuel, p. 222. 1926,

Fuchs, E.-Text-Book of Ophthalmology. Edited by Alexander Duane. 1911.

DUKE-ELDER, W: S. and STALLARD, H. B.-Cases of leuco-sarcoma of the iris Brit Jl. of Ophthal., Vol. XIV, 152. 1930.

Silcock, A. Q.-Trans. Ophthal. Soc. U.K., Vol. XX. 1900.

Baliantyne, A. J.-Diagnosis of sub-retinal tumour. Brit. Jl. of Ophthal., Vol. VI., p. 214- 1922 .

Zentmayer, W.-College of Physicians of Philadelphia. Sect. of Ophthal. 1930.

ShOEMAKER, W: J. and DE Long, $\mathrm{P}_{\star}$-Contrib. Ophthal. Science. Jackson Vol. 146. Wisconsin. 